\title{
Construction technology about the residential system made by the plate-column-light steel structure
}

\author{
Guoqi Xing ${ }^{1, a}$ Haixia Zhu, b \\ ${ }^{1}$ Architectural Engineering Institute, Weifang University, Weifang, Shandong, 261061, China \\ axgq1105@163.com, bhuhaixia_165@163.com
}

\begin{abstract}
Keywords: Plate-column-light steel structure, Building energy efficiency, Hanging column, Hanging board, Construction technology

Abstract. The plate - column -light steel structure building energy-saving residential system has the advantages of light weight and high space utilization and strong ability to resist earthquake high industrialized degree. The construction technology of the plate - column -light steel structure system is researched in this article. Hanging column and hanging board in the plate - column -light steel structure system have important significance for appearance smoothness and external wall thermal insulating technology of residential. In this article the construction technology of hanging column and hanging board is researched with theoretical analysis and practical engineering. The research construction technology for the plate - column -light steel structure system can provide reference for the formulation of the construction technology regulation.
\end{abstract}

\section{Introduction}

Since reform and opening up in china, it is rapid development for the residential construction. Residential construction as a traditional industry in our country is still in the stage of extensive production, for example, single form of residential structure and low degree of industrialization and low labor productivity and low technical content and high energy and raw materials consumption etal. With speeding up of urbanization and expansion of the population and decline of land, it is made us face with severe challenges, so that land saving, energy saving and environmental protection is imminent. In order to adapt to the development of residential construction in our country, various new type energy-saving building structure system of research and development has made gratifying achievements in recent years ${ }^{[1-5]}$, but the ratio of application for new type energy saving residential building system in the actual engineering is not high, because the main reason is that the new energy-saving residential building system exist some questions that difficult to overcome $^{[4]}$, so that the current construction market is hard to accept the above energy saving residential building system.

The latest 《residential building energy-saving design standard》(DB37/5026-2014) require new residential building energy saving standards as high as $75 \%$. To achieve the energy saving target, Shandong Hongtai construction group CO.,LTD develop a new type of plate-column-light steel structure building energy-saving residential system which is structure safety and economical rationality and convenient installation. On the basis of the test the earthquake resistant behavior of the residential system is researched with finite element method ${ }^{[6]}$. The plate - column -light steel structure building energy-saving residential system is integrated assembly by new concrete members and new thermal insulation material and steel structure. The residential system has the advantages of light weight and high space utilization and strong ability to resist earthquake high industrialized degree. In this article the construction technology of the residential system is researched and it can provide reference for the formulation of the construction technology regulation. 


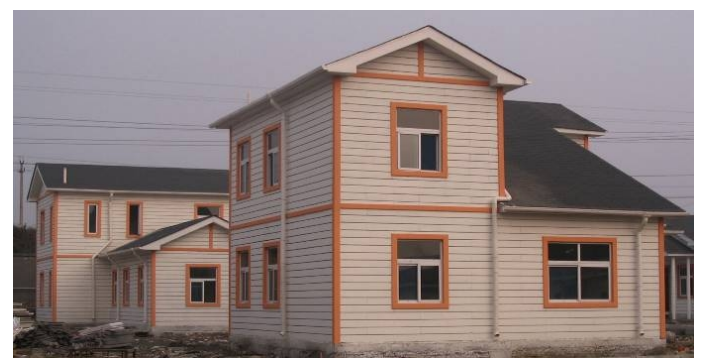

Fig.1 The residential system of plate - column -light steel structure

\section{Feature of the plate - column -light steel structure building energy-saving residential system}

The plate - column -light steel structure is a new structure system that using ecological aggregate concrete cladding panels as the building envelope in the original light steel structure system. According to the building's shape, ecological aggregate concrete cladding panels are designed and arrangement,so it can form sealed envelope. The ecological aggregate concrete cladding panels is made of waste concrete, and it is energy saving and environmental protection and convenient construction, so it can shorten construction cycle of the whole building.

\section{Main points of construction technology}

The main points of whole construction process is the construction of ecological aggregate concrete hanging column and hanging board,and it could very much influence smoothness appearance and building energy requirements of the structure system.

\section{Construction technology}

Construction process. Construction sequence of the hanging column and hanging board is as follows.(1) structure acceptance (2) the basic level preparation(3) hang line and elastic line(4) determine the position of the hanging column according to plate arrangement and hanging column chart(4) install upper and lower connecting piece of hanging column(5) copy of horizontal and vertical line(7) install the hanging column(8) adjust the lug of hanging column and make the corresponding lugs on the same horizontal plane and vertical plane (9) fix hanging column(10)install external hanging board according to plate arrangement and diagonal wrench and make the surface in the same plane after a fixed hanging board(11)install windows and doors(12) install insulation(13)install GRC door and window set(14) seal with sealing paste of building(15) clean surface of hanging board(16) handle surface level of hanging board(17) paint wall with paint

Arrangement of hanging column and hanging board.(1)technical personnel should make technical clarification to the pipe trades and technical personnel and to make clear the line tube position, trend and hole condition in the wall, at the same time according to the design requirements, the detailed arrangement diagram of hanging column and hanging board should be drawn.(2)hanging column and hanging board should be installed after main structure acceptance.(3) levelness and verticality of hanging column and hanging board should be taken care of.(4) dimension survey should be taken on after installation of hanging column and it should require that levelness and verticality should meet the requirements of hanging board.(5) in order to prevent the size deviation in the process of install hanging board,it should strictly control the size after hanging level line.

Construction technology of hanging column and hanging board.(1) receipting goods in construction site: the worker should carefully check the material specifications, models.(2)handling the basic level:it should measure the main structure before putting line, vertical error of the basic level and surface planeness error occured during construction should be adjusted. Surface of the structure should be cleared and the vertical line and horizontal line should be made subsequently. Position line and dividing line of hanging column and hanging board should be made according to design drawings and actual need.(3) position line: horizontal seam position of board and hanging 
position position line shoud accurately hang steel wire and its position is the surface position of hanging board.The worker should often check the correct position of steel wire.(4)the position of hanging column is determined according to plate arrangement and hanging column chart: the positive and negative error of hanging column position should be marked on the structure and the worker could check the installation quality of hanging column according to that and surface size of hanging column handled should meet the requirement of hanging board.(5)the installation of hanging column(shown in fig.2): the installation of hanging column is subsequence after the structure is installed and inspected to be qualified,it should pull to check its flatness during installation process of hanging column,hanging column should be closely connected with the structure. The installation sequence of hanging column is from bottom to top and firstly it should install the fixed part of low end of hanging column and secondly it should install the fixed part of beam and lastly hanging column is installed. The position and the verticality of hanging column should be adjusted during the installation process and it should adjust up and down to make lug on the same horizontal line.

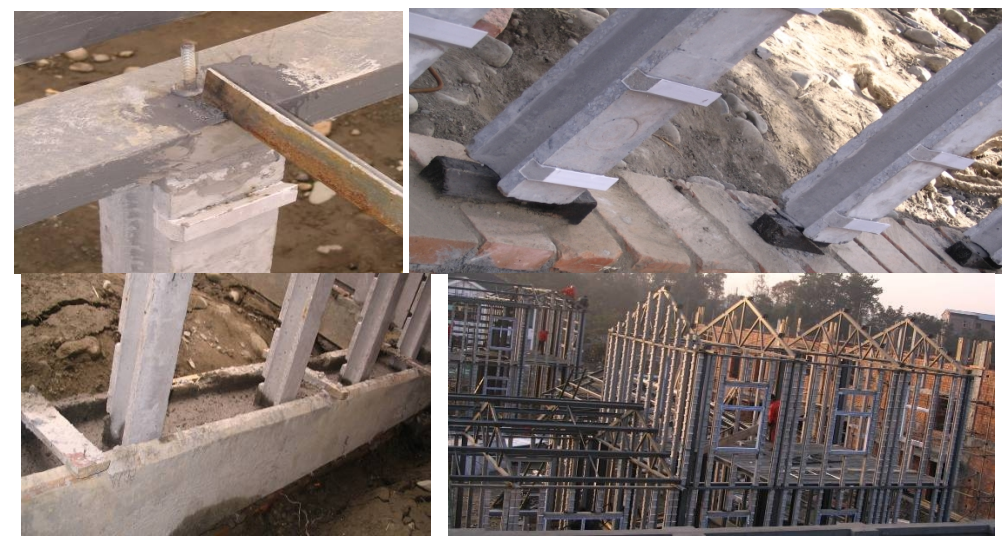

Fig.2 Installation of hanging column

(6) the installation of hanging board(shown in fig.3):it should make the layout and classification stacking of hanging board according to design drawings before construction and flatness, verticality, level degree of hanging column and firmness of hanging claw should be checked, hanging column should be installed according to the order of from the bottom to the top and from the middle to both sides and flatness and straight degree should be checked and timely corrected at any time.

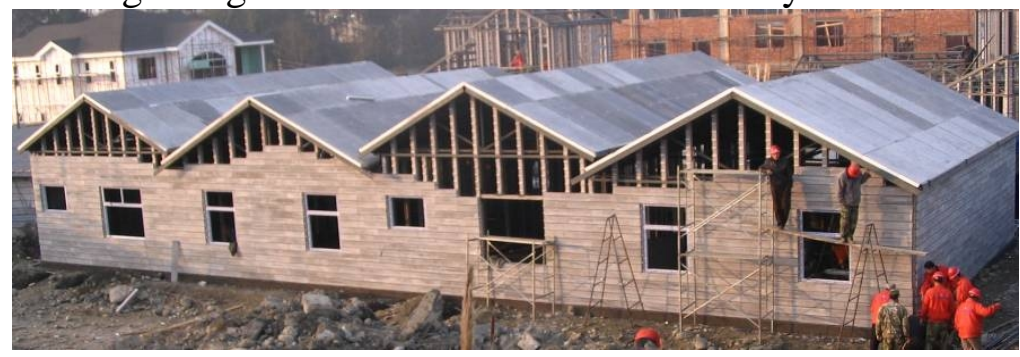

Fig.3 Installation of hanging board

(7) the installation of door and windows lintel and plastic window frames(shown in fig.4): using set aside hole of hanging column and left end of the hole of door and windows lintel, door and windows lintel should be installed with special bolts and anchorage plastic and it should be fixed with L-shaped steel components. At the same time, plastic window frames should be installed in the hole. 


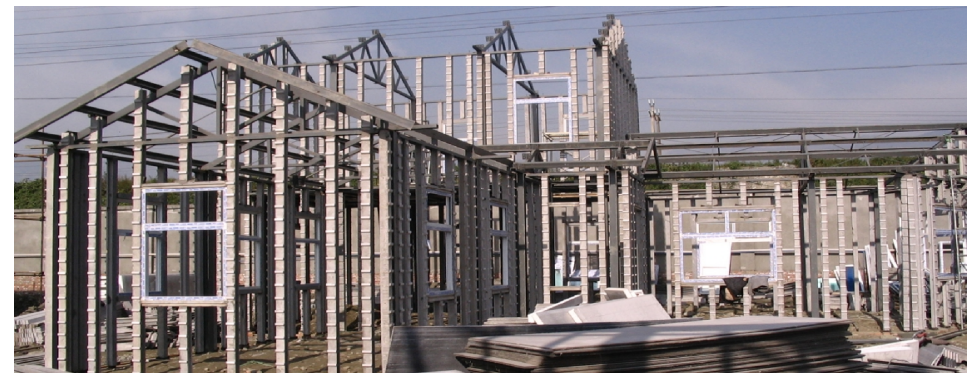

Fig.4 Installation of door and windows lintel and plastic window frames

(8)the installation of inner plate of outside wall(shown in fig.5):firstly it should typesetting and cut the inner plate of outside wall according to the size of layout and install the the inner plate of outside wall with the combined method of adhesive and nailing fixed.

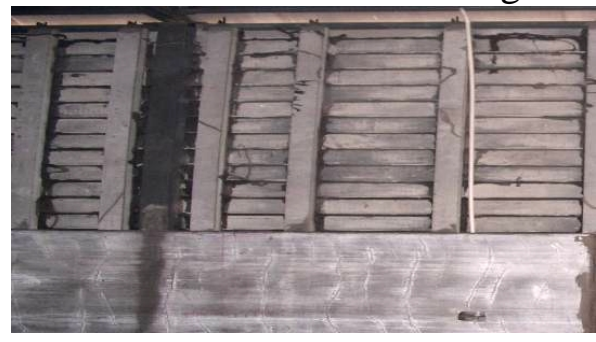

Fig.5 Installation of inner plate of outside wall

(9)the method of external wall insulation: insulation slurry combined according to a certain proportion of blended cement, fly ash, EPS particles using a dedicated slurry mixer, filling machine should be perfusion to the gap of the hanging board and inner plate of external wall and when cement hydration reaction is finished,the composite wall insulation is formed.

(10)the surface of hanging board should be cleaned up and painted.

\section{Conclusions}

The plate - column -light steel structure is a new structure adopting new material and new technology. To promote application of the structural system, the construction technology of the plate - column -light steel structure system is researched based on theoretical analysis and practical engineering. The construction technology of hanging column and hanging board is mainly studied. Because the structure system is a new type of system, there are many problems should be further research and improved in the design and construction for the structure.According to the research of construction of hanging board and hanging column for the structure,it can provide reference for the formulation of construction specifications and large-scale application of the structure.

\section{References}

[1] Fudong Dai, Bolong Zhu and Xinquan Li:Architecture Journal (1998)12 p.15 16,in Chinese.

[2] Dengman Li: Building Technology(2005)18 p.46 47, in chinese.

[3] Qianfeng Yao, Meng Zhang: Industrial Building (2002)8 p.53 56,in Chinese.

[4] Bin Lang, Shifeng Whang: Journal of Qingdao university of science and technology(2005) Vol.26(2) p.1 5, in Chinese.

[5] Construction of tianjin science and technology(2004) 4 P.50, in Chinese. 
[6] Guoqi Xing:CTAS 2011 Advances in Civil Engineering and Architecture Innovation ( 2011 ) p. $142 \sim 145$. 